\title{
Sleep and Anesthesia
}

\author{
Jihyun Song1', Yoo Hyun Um, MD, PhD ${ }^{1,2}$, Tae Won Kim, MD ${ }^{1,2}$, Sung Min Kim, MD ${ }^{1,2}$, \\ So Young Kwon, $\mathrm{MD}^{3}$, Seung-Chul Hong, MD, $\mathrm{PhD}^{1,2}$ \\ 'Sleep Disorders Clinic, Department of Psychiatry, St. Vincent's Hospital, College of Medicine, The Catholic University of Korea, Suwon, Korea \\ 2Departments of Psychiatry, ${ }^{3}$ Anesthesiology and Pain Medicine, St. Vincent's Hospital, College of Medicine, The Catholic University of Korea, \\ Suwon, Korea
}

\footnotetext{
Received: May 15, 2018

Accepted: June 5, 2018

Correspondence

Seung-Chul Hong, MD, $\mathrm{PhD}$

Department of Psychiatry,

St. Vincent's Hospital, College of Medicine,

The Catholic University of Korea,

93 Jungbu-daero, Paldal-gu,

Suwon 16247, Korea

Tel +82-31-249-7114

Fax +82-31-248-6758

E-mail hscjohn@hotmail.com

ORCID

Jihyun Song

https://orcid.org/0000-0002-0128-2869

Yoo Hyun Um

https://orcid.org/0000-0002-3403-4140

Tae Won Kim

https://orcid.org/0000-0003-2689-202X

Sung Min Kim

https://orcid.org/0000-0002-3082-4014

So Young Kwon

https://orcid.org/0000-0003-0249-4190

Seung-Chul Hong

https://orcid.org/0000-0003-0828-2906
}

Since both anesthesia and sleep depress consciousness, bidirectional relationship between them has been further studied. Earlier findings have shown that they share electroencephalographic features and brain regions that are activated in both state of unconsciousness. Despite these similarities, medication-induced sedation provokes different outcome from natural sleep. Enlisting commonly used analgesic drugs, such as benzodiazepines, intravenous agents, benzodiazepine antagonists, opioids, and other adjuvants, the study is comprised of assorted case studies that are clinically applicable or comparable. Acknowledging potential of analgesic drugs on sleep disorders including sleep deprivation, narcolepsy, circadian rhythm disorder, periodic limb movement disorder, and obstructive sleep apnea, the study underscores the clinical importance of studying both fields, sleep and anesthesia. In conclusion, the aim of this review is explaining the consequences of analgesic agents or sedatives on sleep and sleep disorders.

Sleep Med Res 2018;9(1):11-19

Key Words Sleep, Anesthesia, Analgesic drugs, Sedatives, Sleep disorders.

\section{INTRODUCTION}

Anesthesia is medication-induced reversible state of unconsciousness. Since the patients lose senses and mobility during general anesthesia, observed condition of operation is analogous to sleep [1,2]. Thus, abundant studies have studied their bidirectional relationship. Previous studies have persistently disclosed that they partially share biological mechanism, especially through gamma-aminobutyric acid (GABA)ergic pathway [3-7]. Common areas both involved in sleep and anesthesia are found to be GABA positive neurons of ventrolateral preoptic and median preoptic nuclei [8-10], albeit collected evidence is insufficient to articulate the entire mechanism of them [11].

Due to these overlapping brain regions that are activated both in sleep and anesthesia, study on potential role of sedatives and analgesic drugs on sleep is inevitable and clinically important. However, relatively few review articles comprehensively discussed the effect of anesthesia on sleep. The present article therefore reviews how sedatives or analgesic drugs influence sleep related parameters. The study is comprised of commonly used drugs, such as benzodiazepines, anesthetic/analgesic agents, and other adjuvants or stabilizers. Additionally, consequences of analgesic drug in sleep-disordered patients are delineated for future safety of anesthetic subjects. Further studied sleep disorders include sleep deprivation, narcolepsy, circadian rhythm disorder, periodic limb movement, and obstructive sleep apnea syndrome (OSAS). 


\section{ANESTHESIA SLEEP: OVERALL DIFFERENCE IN SEDATION}

Although anesthesia and sleep are considered very much alike, they demonstrate clear differences in their sedation. During general anesthesia, consciousness, pain, and motor function are lost completely. As the anesthesia deepens, low frequency and high amplitude activity increases (Table 1) [12]. Electroencephalography (EEG) activity spreads symmetrically and reaches wider areas of the brain than that in sleep. Also, muscle atonia and resulting apnea may occur. While anesthesia is categorized into four different phases, nocturnal sleep is largely divided into rapid eye movement (REM) sleep and non-rapid eye movement (NREM) sleep. REM sleep occurs at intervals of 90 to $120 \mathrm{~min}$ utes, accompanied by rapid eye movement and muscle tone depression. During three stages within NREM sleep, body temperature and pulse reduce simultaneously. Alike anesthesia, low frequency and high amplitude activity increases as sleep deepens, but EEG activity spreads asymmetrically. During nocturnal sleep, subjects preserve muscle tone and normal breathing. EEG differences between anesthesia and sleep are as follows (Table 2).

Despite aforementioned differences, some phases of anesthesia and stages of natural sleep are parallel to one another. For instance, propofol-induced anesthetic state is similar to NREM sleep. Propofol, anesthetic drug, acts on several brain regions involved in the initiation and maintenance of natural sleep [13]. Likewise, the 'excitement phase' of the anesthesia is comparable to REM sleep [3]. This finding has been validated by research conducted by Steriade et al. [1] Specifically, they treated a sedative to brainstem neurons which are responsible for arousal and REM sleep, and observed the reduction in REM sleep. Such comparable biological mechanism underscores the necessity of studying the effect of anesthesia on sleep.

\section{EFFECT OF COMMONLY USED SEDATIVE AND ANALGESIC DRUGS ON SLEEP (Table 3)}

\section{Benzodiazepines: Midazolam and Diazepam}

Benzodiazepines are analgesic drugs that act through GABA neurotransmitter as natural sleep does. Many of them increase total sleep time and reduce sleep onset latency, while failing to improve the sleep quality [14] and reducing later stage of slow wave sleep (SWS) [15]. Radulovacki et al. [16] purported that benzodiazepine increased only the lighter stage of SWS (SWS1), showing that midazolam-induced anesthesia increased SWS1 by $158 \%$. Meanwhile, diazepam, another benzodiazepine based drug, also increased SWS1 by 255\% and reduced SWS latency by $92 \%[16]$. This finding has been probably due to benzodiaze-

Table 1. Comparison of characteristics of anesthesia and sleep onset, maintenance, and offset [12]

\begin{tabular}{|c|c|c|}
\hline & Anesthesia & Sleep \\
\hline \multirow[t]{3}{*}{ Onset } & - Induced with medication & - Naturally initiated \\
\hline & - Less notable effect of environmental factors & - Notable effect of environmental factors \\
\hline & - Operated regardless of circadian rhythm or homeostasis & - Operated by circadian rhythm \\
\hline \multirow[t]{3}{*}{ Maintenance } & - Dose dependent depth and duration & - Circadian rhythm and daily cycle dependent duration \\
\hline & - Less notable effect of environmental factors & - Cycle of multiple stages of sleep \\
\hline & & - Notable effect of environmental factors \\
\hline \multirow[t]{4}{*}{ Offset } & - Delayed recovery of alertness & - Quick recovery of alertness \\
\hline & - Alertness dependent on dose and duration & - Alertness dependent on duration and circadian rhythm \\
\hline & - Immediate follow-up anesthetization is possible & - Immediate follow-up sleep is difficult \\
\hline & - Probable adverse effects & - Sleep disorders may impair sleep quality \\
\hline
\end{tabular}

Table 2. Anesthesia and sleep: differences in EEG

\begin{tabular}{|c|c|c|c|}
\hline \multicolumn{2}{|r|}{ Anesthesia } & \multicolumn{2}{|r|}{ Sleep } \\
\hline $\begin{array}{l}\text { Phase 1: } \\
\text { Mild anesthesia }\end{array}$ & $\begin{array}{l}\text { - Increased alpha waves and delta waves } \\
\text { - Decreased beta waves }\end{array}$ & REM & $\begin{array}{l}\text { - Saw-tooth waves } \\
\text { - Rapid eye movement in electrooculogram } \\
\text { - Muscle tone depression in electromyogram }\end{array}$ \\
\hline $\begin{array}{l}\text { Phase 2: } \\
\text { Vegetative state }\end{array}$ & $\begin{array}{l}\text { - Increased alpha waves and delta waves in anterior lead } \\
\text { - Decreased beta waves }\end{array}$ & $\begin{array}{l}\text { Stage 1: } \\
\text { NREM }\end{array}$ & - Increased theta waves \\
\hline $\begin{array}{l}\text { Phase 3: } \\
\text { Deep anesthesia }\end{array}$ & $\begin{array}{l}\text { - Burst suppression } \\
\text { - Alternation between flattening alpha waves and delta waves }\end{array}$ & $\begin{array}{l}\text { Stage 2: } \\
\text { NREM }\end{array}$ & $\begin{array}{l}\text { - Sleep spindles } \\
\text { - K complexes }\end{array}$ \\
\hline $\begin{array}{l}\text { Phase 4: } \\
\text { Deepest anesthesia }\end{array}$ & $\begin{array}{l}\text { - Nearly brain death } \\
\text { - Completely lost EEG }\end{array}$ & $\begin{array}{c}\text { Stage } 3-4 \\
\text { NREM }\end{array}$ & $\begin{array}{l}\text { - Delta wave } \\
\text { - (Slow wave) }\end{array}$ \\
\hline
\end{tabular}

REM: rapid eye movement, NREM: non-rapid eye movement, EEG: electroencephalography. 
pine-induced disturbance during sleep. Indeed, midazolam-induced anesthesia resulted in repeated arousal during pharmacological loss of consciousness, which was distinguishable from spontaneous sleep states [17]. Moreover, the effect of midazolam on sleep varied by its applying frequency of application. Daily sedation interruption group, which used midazolam more frequently, exhibited 1) shorter total sleep time, 2) higher arousal frequency, and 3) longer REM sleep and Stage 3 and 4 sleep than continuous sedation group [18].

Benzodiazepines also significantly affect respiratory status of patients. Midazolam lowers the muscle activity during deep anesthesia, thereby increases the possibility of airway stenosis than it does in natural sleep. Genta et al. [19] noted that midazolaminduced sedation may increase collapsibility of upper airway muscle. On the other hand, diazepam possibly reduces sleep apnea and increases the percentage of NREM sleep in rats [20]. Also, Wedzicha et al. [21] stated that diazepam improved sleep duration in patients with chronic airflow obstruction. However, the usage potentially leads to adverse effects including hypothermia, tachycardia, hypertension, and partial memory impairment [22-24].

\section{Intravenous Anesthetic Agent: Propofol and Ketamine}

Propofol is one of intravenous anesthetic agents that has char- acteristically short half life, thereby does not have prolonged effect [25]. However, it is observed to negatively influence patient's sleep after anesthesia by delaying sleep latency and reducing Stage 2 latency in drug-induced sleep [26]. To back up further, it exacerbated poor sleep quality of critically ill patients and reduced percentage of REM sleep [27]. Besides, there were conflicting findings that propofol improved sleep quality in patients in Intensive Care Unit [28]. In consistent with such findings, propofol therapy improved polysomnographic and Leeds Sleep Evaluation Questionnaire result of patients with refractory chronic primary insomnia [29]. Thus, in depth research is recommended to examine the effect of propofol infusion on sleep since it varies by circumstances.

However, propofol shows consistent postoperative outcome in patients with OSAS. According to the fact that propofol deters genioglossus activity [30], abundant studies have revealed that propofol infusion instigates significantly higher rate of airway collapse in dose dependent manner [30,31]. Along with the aforementioned results, the symptoms of OSAS measured by apnea-hypopnea index and oxygen desaturation level remained constant during the propofol sedation [32-36].

Ketamine is another intravenous anesthetic agent that affects sleep significantly. Some studies have found that ketamine helps NREM sleep, especially SWS both in animal model and patients $[37,38]$. Indeed, it increased slow wave for the first night

Table 3. Effect of commonly used sedatives and analgesic drugs on sleep

\begin{tabular}{|c|c|c|}
\hline \multicolumn{2}{|c|}{ Substance } & \multirow[b]{2}{*}{ Reduce sleep onset latency } \\
\hline Benzodiazepines & Midazolam and & \\
\hline & Diazepam & Worsen sleep quality \\
\hline & & Reduce later stage of SWS \\
\hline & & Increase airway collapsibility \\
\hline \multirow[t]{7}{*}{ Intravenous anesthetic agent } & Propofol & Varies by circumstances \\
\hline & & May improve or exacerbate poor sleep quality \\
\hline & & Increase airway collapsibility \\
\hline & Ketamine & Increase SWA \\
\hline & & Reduce number of awakenings \\
\hline & & Induce psychotropic side effects during sleep \\
\hline & & Avoids respiratory events \\
\hline \multirow[t]{5}{*}{ Analgesic Agent } & Opioids & Worsen sleep quality \\
\hline & & Reduce SWS and REM sleep \\
\hline & & Increase Stage 1 sleep \\
\hline & & May induce respiratory suppression \\
\hline & & Favorable effect on patients with periodic limb movement \\
\hline \multirow[t]{5}{*}{ Benzodiazepine antagonist } & Flumazenil & Improve sleep quality \\
\hline & & Increase sleep efficiency and SWS \\
\hline & & Treat EDS and hypersomnolence \\
\hline & & Unfavorable effect on sleep deprived patients \\
\hline & & No effect on respiratory pathway \\
\hline \multirow[t]{2}{*}{ Other Adjuvant } & Dexmedetomidine & More aroused after anesthesia \\
\hline & & Avoids respiratory events \\
\hline
\end{tabular}

SWS: slow wave sleep, REM: rapid eye movement. 
of usage, while it subsequently increased total sleep and reduced number of awakenings for the second night [39]. However, it also demonstrated deleterious impact on sleep electrophysiology by inducing psychotropic side effects and unpleasant dreams during drug-induced sleep $[40,41]$. In case of cats, it triggered hallucination due to malfunction in central nervous system [42].

Mounting evidence has suggested that ketamine favorably acts on respiratory tract during anesthesia. Studies on pharmacology of ketamine indicate that it alters airway muscle movement and tranquilizes respiratory activity by reducing the release of acetylcholine in medial pontine reticular formation $[38,43,44]$. In rat model, ketamine has found to be doing so by increasing viscoelasticity of lung and influencing alveoli [45]. Aforementioned results demonstrate ketamine as a promising sedative for the patients with OSAS because it highly avoids respiratory events during anesthesia $[46,47]$.

\section{Analgesic Agent: Opioids}

Opioid is an analgesic agent frequently used as pain reliever. There have been contentions about the effect of opioids on sleep, whether it is beneficial or not [48]. Meanwhile, many studies have implied that opioid has detrimental effect on sleep. Polysomnographical results and sleep diaries of opioid dependent patients have suggested that opioid is linearly correlated to poor sleep quality and reduction of SWS $[49,50]$. A significant decrease in SWS is highly liable to opioid, because opioid antagonist (naloxone) application successfully revitalizes SWS [51]. Disadvantageous consequence of opioid on sleep also has been recognized in other sleep stages. For instance, it significantly reduces REM sleep and increases Stage 1 sleep by impeding acetylcholine release in medial pontine reticular formation [51-54].

As respiratory depressant, opioid also detrimentally affects sleep disordered breathing and thereby increases number of awakenings. Numerous studies have exposed high correlation between opioid and respiratory deficiency, such as central sleep apnea and hypoxemia [52,55-64]. The severity of respiratory obstruction increases in dose dependent manner [56,65].

However, we need to consider that the patients who receive opioid prescription already have low quality of sleep as a result of pain. Mostly pain causes higher number of arousal, thus patients may accommodate daytime sleepiness and napping regardless of opioid [66,67]. Indeed, Cronin et al. [68,69] indicates that poor sleep quality has maintained even after opioid has been removed from patients. He also articulates that there has been no incident of airway obstruction when patients without OSAS used opioid [68]. Additionally, one review article even states that opioid analgesia significantly improves the sleep quality of patients [70]. For instance, opioid has been found to be a useful treatment of restless leg syndrome or periodic limb movement [71]. In several studies, opioid significantly reduced periodic limb movement index and increased percentage of
SWS [72,73].

\section{Benzodiazepine Antagonist: Flumazenil}

Benzodiazepine antagonist such as flumazenil deters sleep and increases alertness through GABAergic pathway [74]. Thus, it is commonly applied in order to reverse sedation during the recovery after anesthesia. Extent research has disclosed that flumazenil treated hypersomnolence or excessive daytime sleepiness by improving nocturnal sleep quality. Specifically, polysomnographic outcome reveals that flumazenil increases sleep efficiency and SWS, and reduces sleep onset latency [75,76]. However, for the sleep deprived patients, it rather lengthens sleep onset latency and disturbs SWS [77]. Moreover, according to the study conducted by Schönhofer and Kohler [78], it has no effect on respiratory pathway thus can be applied to the patients with OSAS.

\section{Other Adjuvant: Dexmedetomidine}

Dexmedetomidine is common adjuvant used in the process of anesthesia. It is an antagonist of the $\alpha 2$-adrenergic receptor, engendering the sedation that resembles sleep Stage $2[79,80]$. Alike most of analgesic drugs, it follows GABAergic pathway and shares a common biological pathway with natural sleep [79]. Since it maintains high level of thalamic connectivity, patient anesthetized with dexmedetomidine tends to be more aroused after the surgery [81].

As well as ketamine, it is known to provide sedation without the risk of respiratory depression. The need for artificial airway support during anesthesia has been significantly less in dexmedetomidine than that in other analgesic drugs [82]. Therefore, it is beneficial to patients with sleep apnea, especially children and adolescents who have unsettled airway [80].

\section{CONSEQUENCES OF ANESTHESIA IN SLEEP DISORDERED PATIENTS}

\section{Sleep Deprivation}

Since anesthesia and sleep share behavioral context, sleep deprivation is compensated during anesthetic state. Anesthesia alleviates fatigue and fatigue itself may further promote anesthesia vice versa [83]. In rat model, 12 hours of sleep deprivation led to more rapid loss of consciousness in sevoflurane-induced anesthesia [84]. Other studies that induced anesthesia with propofol or intralipid control in rats with sleep deprivation also have revealed similar outcome. After 6 hours of anesthesthetic process, sleep deprived rats did not demonstrate any distinguishable deprived characteristic in REM sleep and NREM sleep [83]. Isoflurane, desflurane and halothane also successfully supplemented sleep deprivation, while isoflurane and desflurane compensated NREM sleep debt twice faster than that of propofol [84-86]. However, in the case of inhaled anesthetic agent 
(halogenated ethers), the anesthetic state was subsequent to NREM sleep, and REM sleep debt was not compensated [87]. Clinical trials with healthy persons were not significantly different with aforementioned outcomes. Induction of isoflurane reduced sleepiness and increased Stage 2 sleep in sleep deprived patients [88]. As it can be seen in multiple animal and human models, sleep deprivation complementation varies depending on the analgesic drugs.

\section{Narcolepsy}

Narcolepsy is a sleep disorder mostly characterized by intolerable excessive daytime sleepiness, cataplexy, and orexin deficiency. Orexinergic neurons are most divergent at wake state and generally remain low during sleep. Since it is highly correlated with gamma waves and muscle activity, an abnormality in orexinergic signaling pathway causes narcolepsy [89].

Several studies have concordantly delineated that orexin and analgesic drugs are highly correlated. Kushikata et al. [90,91] have indicated that barbiturates possibly target orexinergic neurons . Moreover, when orexin was injected to the cortex, the anesthetic effect of propofol was reduced [92]. Hypothetical mechanism is that orexinergic system promotes arousal under propofol-induced anesthesia, which is mediated by noradrenergic and dopaminergic neurotransmission of the cerebral cortex [93]. Likewise, when orexin was injected into the basal forebrain of anesthetized rats, they were alert and the time to fully anesthesize them was reduced $[94,95]$. Conversely, the activity of orexinergic neurons reduced in rats injected with sevoflurane and isoflurane [96]. Interestingly, this phenomenon did not appear when halothane was injected, suggesting that halothaneinduced anesthesia did not participate in orexinergic signaling pathway [97]. Following issue is anesthesia in narcolepsy patients would look different from that in normal patients. Indeed, patients with narcolepsy have demonstrated similar intraoperative course and recovery period that are similar to healthy controls [98]. Also, their risk of postoperative complications have not been significantly higher than that of other groups [99]. To back up further, propofol and remifentanil have been found to be safe during heart surgery in narcoleptics [100]. Besides, $\mathrm{Hu}$ et al. [101] listed some recommendations for the clinicians who are performing anesthesia on narcoleptics. In general, when anesthesia is conducted to patients with narcolepsy, sedation should be prevented and the treatment of narcolepsy should be continued until the day of operation. Use of short-acting anesthetics, such as propofol and remifentanil, is recommended [101]. It is also necessary to pay attention to the interaction with the patient's existing drugs, such as stimulants such as modafinil [101]. Meanwhile, bispectral index monitoring is advantageous to preserve sevoflurane concentration at a reasonable level and to observe changes in status which are due to oversedation and preoperative drug use [101]. Furthermore, studies on mice with orexin deficiency have indicated that the control of temperature is important in patients with narcolepsy during anesthesia [102]. For neurosurgical anesthetic operations involving the hypothalamus or the third and fourth ventricles, postoperative symptoms of narcoleptics should be checked after the surgery [103].

\section{Circadian Rhythm Disorder}

Patients conceivably experience sleep disturbances after anesthesia because anesthesia distresses circadian rhythm after surgery. Both animal and human models have shown that anesthesia impedes the rhythm of the daily cycle and changes the molecular clock. Recent study has displayed that sevofluraneinduced anesthesia suppresses the expression of clock genes [104]. Also, benzodiazepines influence the major neurotransmitter systems, which is associated with circadian rhythm control [105]. Plenty of studies have revealed that diurnal rhythm would be interfered when an animal is anesthetized during its active time [106]. However, much more evidence is needed to validate how anesthesia-induced change in the molecular clock renders change in behavior.

Disruption of circadian rhythm after anesthesia is heavily correlated to melatonin, an important agent that maintains circadian cycle. In fact, the level of melatonin metabolites has been increased while that of cortisol has been decreased after anesthesia [107]. Hence, melatonin is commonly used as a stabilizer when performing surgery with anesthesia. Oral administration of melatonin to patients undergoing local anesthesia has provided satisfactory surgical conditions due to anxiolytic effects, pain relief, and reduction of ocular motility disorders [108-110]. Indeed, a study illustrates that oral melatonin reduces the incidence of excitement after sevoflurane anesthesia [111]. Furthermore, several study approaches have presented that melatonin acts to mitigate apoptotic neurodegeneration caused by anesthesia. A study conducted on rats that were exposed to pro-apoptotic anesthesia cocktail (such as midazolam, isoflurane, and nitrous oxide) for seven days has reported that their anesthesiainduced brain damage significantly decreased after the application of melatonin [112,113]. In conclusion, melatonin is an effective treatment to reduce patient anxiety, to reduce the pain associated with hemostasis, and to improve preoperative damage before and after anesthesia [114].

\section{Periodic Limb Movement Disorder and Restless Legs Syndrome}

Abundant research has studied the correlation between anesthesia and abnormal movement in legs. They have denoted that spinal anesthesia spurs or worsens malfunction in motor activity, thereby leading periodic limb movement disorder (PLMD) or restless legs syndrome (RLS) [115-118]. Several anesthesia-related PLMD cases have implied that anesthetic agents affect spinal cord and hematocele [116,118]. Historically, benzodiazepines and ketamine have been applied as anesthetic agent and 
treatment for PLMD and RLS [119,120]. However, among anesthetic drugs, opioids have been disclosed as the most influential for the disorder [121].

\section{Obstructive Sleep Apnea}

As we have delineated in previous section, several anesthetic agents and sedatives significantly disturb respiratory tract. Postoperative adverse risks are severe and recognizable in patients with OSAS [122]. Indeed, opioids and some sedatives potentially increase respiratory events, thereby should be excluded in surgery [123]. Thus, it is clinically crucial to acknowledge the effect of anesthetic drug on OSAS. Compensating such need, several group of researchers have published consensus statement or reviews for anesthesia in obstructive sleep apnea (OSA) patients, emphasizing the significance of comprehensive diagnosis of OSAS and reiterating avoided drugs before anesthesia [124-126].

\section{CONCLUSION}

Most analgesic agents and sedatives associated with anesthesia act on several brain regions involved in the initiation and maintenance of natural sleep. Since both anesthesia and sleep share biological mechanism via GABAergic pathway, they significantly impact each other. This may engender neurological damage and aforementioned sleep disorders, such as circadian rhythm disorder, PLMD, OSA. In order to avoid such adverse effects, acknowledging the consequence of anesthesia on sleep is clinically essential. Moreover, discovering thorough correlation between sleep and anesthesia potentially instigates novel therapeutic analysis. As stated above, analgesic agents possess a capability to be a desirable treatment of sleep disorders, and possibly vice versa. Thus, collaborative research in sleep and anesthesia opens new research avenues in both fields of study.

\section{Conflicts of Interest}

The authors have no financial conflicts of interest.

\section{Authors' Contribution}

Conceptualization: Hong SC. Project administration: Hong SC. Supervision: Hong SC. Validation: Hong SC, Kwon SY. Writing_-original draft: Song JH. Writing—review \& editing: Um YH, Kim TW, Kim SM, Kwon SY.

\section{REFERENCES}

1. Steriade M, McCormick DA, Sejnowski TJ. Thalamocortical oscillations in the sleeping and aroused brain. Science 1993;262:679-85.

2. Mashour GA, Pal D. Interfaces of sleep and anesthesia. Anesthesiol Clin 2012;30:385-98

3. Keifer J. Sleep and anesthesia. In: Antognini JF, Carstens E, Raines DE, eds. Neural mechanisms of anesthesia. Totowa, NJ: Humana Press 2003;65-74.

4. Holmes SW, Sugden D. The effects of GABAtransaminase (GABA-T) inhibition on sleep and behavior of the cat. Sleep Res 1975;4:78.

5. Gottesmann C. GABA mechanisms and sleep. Neuroscience 2002;111: 231-9.
6. Nelson LE, Guo TZ, Lu J, Saper CB, Franks NP, Maze M. The sedative component of anesthesia is mediated by GABA(A) receptors in an endogenous sleep pathway. Nat Neurosci 2002;5:979-84.

7. Lu J, Nelson LE, Franks N, Maze M, Chamberlin NL, Saper CB. Role of endogenous sleep-wake and analgesic systems in anesthesia. J Comp Neurol 2008;508:648-62.

8. Keifer JC, Baghdoyan HA, Lydic R. Sleep disruption and increased apneas after pontine microinjection of morphine. Anesthesiology 1992;77: 973-82.

9. Szymusiak R, McGinty D. Hypothalamic regulation of sleep and arousal. Ann NY Acad Sci 2008;1129:275-86.

10. Strecker RE, Nalwalk J, Dauphin LJ, Thakkar MM, Chen Y, Ramesh V, et al. Extracellular histamine levels in the feline preoptic/anterior hypothalamic area during natural sleep-wakefulness and prolonged wakefulness: an in vivo microdialysis study. Neuroscience 2002;113:663-70.

11. Eikermann M, Vetrivelan R, Grosse-Sundrup M, Henry ME, Hoffmann $\mathrm{U}$, Yokota $\mathrm{S}$, et al. The ventrolateral preoptic nucleus is not required for isoflurane general anesthesia. Brain Res 2011;1426:30-7.

12. Lydic R. Pain: a bridge linking anesthesiology and sleep research. Sleep 2001;24:10-2.

13. Murphy M, Bruno MA, Riedner BA, Boveroux P, Noirhomme Q, Landsness EC, et al. Propofol anesthesia and sleep: a high-density EEG study. Sleep 2011;34:283-91.

14. Barbara MS. Diazepam and its hydroxylated metabolites: studies on sleep in healthy man. Br J Clin Pharmacol 1979;8(Suppl 1): 57S-61S.

15. Livezey GT, Radulovacki M, Isaac L, Marczynski TJ. Prenatal exposure to diazepam results in enduring reductions in brain receptors and deep slow wave sleep. Brain Res 1985;334:361-5.

16. Radulovacki M, Sreckovic G, Zak R, Zahrebelski G. Diazepam and midazolam increase light slow-wave sleep (SWS1) and decrease wakefulness in rats. Brain Res 1984;303:194-6.

17. Ferrarelli F, Massimini M, Sarasso S, Casali A, Riedner BA, Angelini G, et al. Breakdown in cortical effective connectivity during midazolaminduced loss of consciousness. Proc Natl Acad Sci USA 2010;107:2681-6.

18. Oto J, Yamamoto K, Koike S, Imanaka H, Nishimura M. Effect of daily sedative interruption on sleep stages of mechanically ventilated patients receiving midazolam by infusion. Anaesth Intensive Care 2011;39:392400.

19. Genta PR, Eckert DJ, Gregorio MG, Danzi NJ, Moriya HT, Malhotra A, et al. Critical closing pressure during midazolam-induced sleep. $J$ Appl Physiol (1985) 2011;111:1315-22.

20. Carley DW, Trbovic SM, Radulovacki M. Diazepam suppresses sleep apneas in rats. Am J Respir Crit Care Med 1998;157:917-20.

21. Wedzicha JA, Wallis PJ, Ingram DA, Empey DW. Effect of diazepam on sleep in patients with chronic airflow obstruction. Thorax 1988;43:72930.

22. Mailliet F, Galloux P, Poisson D. Comparative effects of melatonin, zolpidem and diazepam on sleep, body temperature, blood pressure and heart rate measured by radiotelemetry in Wistar rats. Psychopharmacology (Berl) 2001;156:417-26.

23. Gorissen M, Tielemans M, Coenen A. Alertness and memory after sleep deprivation and diazepam intake. J Psychopharmacol 1997;11:233-9.

24. Coenen AM, van Luijtelaar EL. Effects of benzodiazepines, sleep and sleep deprivation on vigilance and memory. Acta Neurol Belg 1997;97: 123-9.

25. Scarth E, Smith S. Drugs in anaesthesia and intensive care. Oxford: Oxford University Press 2016.

26. Ozone M, Itoh H, Yamadera W, Ohbuchi K, Hayashida K, Sasaki M, et al. Changes in subjective sleepiness, subjective fatigue and nocturnal sleep after anaesthesia with propofol. Psychiatry Clin Neurosci 2000; 54:317-8.

27. Kondili E, Alexopoulou C, Xirouchaki N, Georgopoulos D. Effects of propofol on sleep quality in mechanically ventilated critically ill patients: a physiological study. Intensive Care Med 2012;38:1640-6.

28. Treggiari-Venzi M, Borgeat A, Fuchs-Buder T, Gachoud JP, Suter PM. 
Overnight sedation with midazolam or propofol in the ICU: effects on sleep quality, anxiety and depression. Intensive Care Med 1996;22:118690.

29. Xu Z, Jiang X, Li W, Gao D, Li X, Liu J. Propofol-induced sleep: efficacy and safety in patients with refractory chronic primary insomnia. Cell Biochem Biophys 2011;60:161-6.

30. Hillman DR, Walsh JH, Maddison KJ, Platt PR, Kirkness JP, Noffsinger WJ, et al. Evolution of changes in upper airway collapsibility during slow induction of anesthesia with propofol. Anesthesiology 2009;111: 63-71.

31. Eastwood PR, Platt PR, Shepherd K, Maddison K, Hillman DR. Collapsibility of the upper airway at different concentrations of propofol anesthesia. Anesthesiology 2005;103:470-7.

32. Rabelo FA, Braga A, Küpper DS, De Oliveira JA, Lopes FM, de Lima Mattos PL, et al. Propofol-induced sleep: polysomnographic evaluation of patients with obstructive sleep apnea and controls. Otolaryngol Head Neck Surg 2010;142:218-24.

33. Rabelo FA, Küpper DS, Sander HH, Fernandes RM, Valera FC. Polysomnographic evaluation of propofol-induced sleep in patients with respiratory sleep disorders and controls. Laryngoscope 2013;123:2300-5.

34. Atkins JH, Mandel JE, Rosanova G. Safety and efficacy of drug-induced sleep endoscopy using a probability ramp propofol infusion system in patients with severe obstructive sleep apnea. Anesth Analg 2014; 119:805-10.

35. Capasso R, Rosa T, Tsou DY, Nekhendzy V, Drover D, Collins J, et al. Variable Findings for Drug-Induced Sleep Endoscopy in Obstructive Sleep Apnea with Propofol versus Dexmedetomidine. Otolaryngol Head Neck Surg 2016;154:765-70.

36. Evans RG, Crawford MW, Noseworthy MD, Yoo SJ. Effect of increasing depth of propofol anesthesia on upper airway configuration in children. Anesthesiology 2003;99:596-602.

37. Takahashi S, Kushikata T, Matsuki A. Effects of isoflurane and ketamine on sleep in rabbits. Psychiatry Clin Neurosci 2001;55:239-40.

38. Lydic R, Baghdoyan HA. Ketamine and MK-801 decrease acetylcholine release in the pontine reticular formation, slow breathing, and disrupt sleep. Sleep 2002;25:615-20.

39. Duncan WC, Zarate CA. Ketamine, sleep, and depression: current status and new questions. Curr Psychiatry Rep 2013;15:394.

40. Blagrove M, Morgan CJ, Curran HV, Bromley L, Brandner B. The incidence of unpleasant dreams after sub-anaesthetic ketamine. Psychopharmacology (Berl) 2009;203:109-20.

41. Wanna O, Werawatganon T, Piriyakitphaiboon S, Taesiri B. A comparison of propofol and ketamine as induction agents for cesarean section. J Med Assoc Thai 2004;87:774-9.

42. Mori K, Kawamata M, Mitani H, Yamazaki Y, Fujita M. A neurophysiologic study of ketamine anesthesia in the cat. Anesthesiology 1971;35: 373-82.

43. Idvall J, Ahlgren I, Aronsen KR, Stenberg P. Ketamine infusions: pharmacokinetics and clinical effects. Br J Anaesth 1979;51:1167-73.

44. Eikermann M, Grosse-Sundrup M, Zaremba S, Henry ME, Bittner EA, Hoffmann U, et al. Ketamine activates breathing and abolishes the coupling between loss of consciousness and upper airway dilator muscle dysfunction. Anesthesiology 2012;116:35-46.

45. Alves-Neto O, Tavares P, Rocco PR, Zin WA. Respiratory mechanics and morphometric changes during anesthesia with ketamine in normal rats. Braz J Med Biol Res 2001;34:1217-23.

46. Brown DL. Use of ketamine to wean a patient with sleep apnea. Crit Care Med 1986;14:167-8.

47. Drummond GB. Comparison of sedation with midazolam and ketamine: effects on airway muscle activity. Br J Anaesth 1996;76:663-7.

48. Cheatle MD, Webster LR. Opioid Therapy and Sleep Disorders: Risks and Mitigation Strategies. Pain Med 2015;16(Suppl 1):S22-6.

49. Sharkey KM, Kurth ME, Anderson BJ, Corso RP, Millman RP, Stein MD. Assessing sleep in opioid dependence: a comparison of subjective ratings, sleep diaries, and home polysomnography in methadone main- tenance patients. Drug Alcohol Depend 2011;113:245-8.

50. Dimsdale JE, Norman D, DeJardin D, Wallace MS. The effect of opioids on sleep architecture. J Clin Sleep Med 2007;3:33-6.

51. Reinoso-Barbero F, de Andrés I. Effects of opioid microinjections in the nucleus of the solitary tract on the sleep-wakefulness cycle states in cats. Anesthesiology 1995;82:144-52.

52. Wang D, Teichtahl H. Opioids, sleep architecture and sleep-disordered breathing. Sleep Med Rev 2007;11:35-46.

53. Przewłocka B, Mogilnicka E, Lasón W, van Luijtelaar EL, Coenen AM. Deprivation of REM sleep in the rat and the opioid peptides beta-endorphin and dynorphin. Neurosci Lett 1986;70:138-42.

54. Steinfels GF, Young GA, Khazan N. Opioid self-administration and REM sleep EEG power spectra. Neuropharmacology 1980;19:69-74.

55. Javaheri S, Randerath WJ. Opioid-induced central sleep apnea: mechanisms and therapies. Sleep Medicine Clinics 2014;9:49-56.

56. Lee-Iannotti J, Parish JM. The epidemic of opioid use: implications for the sleep physician. J Clin Sleep Med 2014;10:645-6.

57. Teichtahl H, Wang D, Cunnington D, Quinnell T, Tran H, Kronborg I, et al. Ventilatory responses to hypoxia and hypercapnia in stable methadone maintenance treatment patients. Chest 2005;128:1339-47.

58. Randerath WJ, George S. Opioid-induced sleep apnea: is it a real problem? J Clin Sleep Med 2012;8:577-8.

59. Alattar MA, Scharf SM. Opioid-associated central sleep apnea: a case series. Sleep Breath 2009;13:201-6.

60. Webster LR, Choi Y, Desai H, Webster L, Grant BJ. Sleep-disordered breathing and chronic opioid therapy. Pain Med 2008;9:425-32.

61. Mogri M, Desai H, Webster L, Grant BJ, Mador MJ. Hypoxemia in patients on chronic opiate therapy with and without sleep apnea. Sleep Breath 2009;13:49-57.

62. Doufas AG, Tian L, Padrez KA, Suwanprathes P, Cardell JA, Maecker HT, et al. Experimental pain and opioid analgesia in volunteers at high risk for obstructive sleep apnea. PLoS One 2013;8:e54807.

63. Benyamin R, Trescot AM, Datta S, Buenaventura R, Adlaka R, Sehgal N, et al. Opioid complications and side effects. Pain Physician 2008; 11(2 Suppl):S105-20.

64. Yue HJ, Guilleminault C. Opioid medication and sleep-disordered breathing. Medical Clinics 2010;94:435-46.

65. Brown KA, Laferrière A, Moss IR. Recurrent hypoxemia in young children with obstructive sleep apnea is associated with reduced opioid requirement for analgesia. Anesthesiology 2004;100:806-10.

66. Zgierska A, Brown RT, Zuelsdorff M, Brown D, Zhang Z, Fleming MF. Sleep and daytime sleepiness problems among patients with chronic noncancerous pain receiving long-term opioid therapy: a cross-sectional study. J Opioid Manag 2007;3:317-27.

67. Parker RK, Holtmann B, White PF. Effects of a nighttime opioid infusion with PCA therapy on patient comfort and analgesic requirements after abdominal hysterectomy. Anesthesiology 1992;76:362-7.

68. Cronin AJ, Keifer JC, Davies MF, King TS, Bixler EO. Postoperative sleep disturbance: influences of opioids and pain in humans. Sleep 2001; 24:39-44.

69. Cronin A, Keifer JC, Baghdoyan HA, Lydic R. Opioid inhibition of rapid eye movement sleep by a specific mu receptor agonist. $\mathrm{Br} J \mathrm{An}$ aesth 1995;74:188-92.

70. Brennan MJ, Lieberman JA 3rd. Sleep disturbances in patients with chronic pain: effectively managing opioid analgesia to improve outcomes. Curr Med Res Opin 2009;25:1045-55.

71. Hening WA, Walters A, Kavey N, Gidro-Frank S, Côté L, Fahn S. Dyskinesias while awake and periodic movements in sleep in restless legs syndrome: treatment with opioids. Neurology 1986;36:1363-6.

72. Kavey N, Walters AS, Hening W, Gidro-Frank S. Opioid treatment of periodic movements in sleep in patients without restless legs. Neuropeptides 1988;11:181-4.

73. Winkelmann J, Schadrack J, Wetter TC, Zieglgänsberger W, Trenkwalder C. Opioid and dopamine antagonist drug challenges in untreated restless legs syndrome patients. Sleep Med 2001;2:57-61. 
74. Zheng TM, Caruncho HJ, Zhu WJ, Vicini S, Ikonomovic S, Grayson DR, et al. Chronic flumazenil alters GABA(A) receptor subunit mRNA expression, translation product assembly and channel function in neuronal cultures. J Pharmacol Exp Ther 1996;277:525-33.

75. Trotti LM, Saini P, Koola C, LaBarbera V, Bliwise DL, Rye DB. Flumazenil for the treatment of refractory hypersomnolence: clinical experience with 153 patients. J Clin Sleep Med 2016;12:1389-94.

76. Ozone M, Itoh H, Ohbuchi K, Ohyama E, Hayashida K, Sato M, et al. The effects of flumazenil on sleepiness, task performance and nocturnal sleep after anesthesia with midazolam. Psychiatry Clin Neurosci 2001; 55:235-7.

77. Seifritz E, Hemmeter U, Trachsel L, Lauer CJ, Hatzinger M, Emrich HM, et al. Effects of flumazenil on recovery sleep and hormonal secretion after sleep deprivation in male controls. Psychopharmacology (Berl) 1995;120:449-56.

78. Schönhofer B, Köhler D. Benzodiazepine receptor antagonist (flumazenil) does not affect sleep-related breathing disorders. Eur Respir J 1996;9:1816-20.

79. Nelson LE, Lu J, Guo T, Saper CB, Franks NP, Maze M. The alpha2adrenoceptor agonist dexmedetomidine converges on an endogenous sleep-promoting pathway to exert its sedative effects. Anesthesiology 2003;98:428-36.

80. Mahmoud M, Jung D, Salisbury S, McAuliffe J, Gunter J, Patio M, et al. Effect of increasing depth of dexmedetomidine and propofol anesthesia on upper airway morphology in children and adolescents with obstructive sleep apnea. J Clin Anesth 2013;25:529-41.

81. Guldenmund P, Vanhaudenhuyse A, Sanders RD, Sleigh J, Bruno MA, Demertzi A, et al. Brain functional connectivity differentiates dexmedetomidine from propofol and natural sleep. Br J Anaesth 2017;119: 674-84.

82. Mahmoud M, Gunter J, Donnelly LF, Wang Y, Nick TG, Sadhasivam S. A comparison of dexmedetomidine with propofol for magnetic resonance imaging sleep studies in children. Anesth Analg 2009;109:745-53.

83. Tung A, Bergmann BM, Herrera S, Cao D, Mendelson WB. Recovery from sleep deprivation occurs during propofol anesthesia. Anesthesiology 2004;100:1419-26.

84. Pal D, Lipinski WJ, Walker AJ, Turner AM, Mashour GA. State-specific effects of sevoflurane anesthesia on sleep homeostasis: selective recovery of slow wave but not rapid eye movement sleep. Anesthesiology 2011;114:302-10.

85. Nelson AB, Faraguna U, Tononi G, Cirelli C. Effects of anesthesia on the response to sleep deprivation. Sleep 2010;33:1659-67.

86. Pick J, Chen Y, Moore JT, Sun Y, Wyner AJ, Friedman EB, et al. Rapid eye movement sleep debt accrues in mice exposed to volatile anesthetics. Anesthesiology 2011;115:702-12.

87. Mashour GA, Lipinski WJ, Matlen LB, Walker AJ, Turner AM, Schoen $\mathrm{W}$, et al. Isoflurane anesthesia does not satisfy the homeostatic need for rapid eye movement sleep. Anesth Analg 2010;110:1283-9.

88. Tung A, Szafran MJ, Bluhm B, Mendelson WB. Sleep deprivation potentiates the onset and duration of loss of righting reflex induced by propofol and isoflurane. Anesthesiology 2002;97:906-11.

89. Sakurai T, Pandi-Perumal SR, Monti JM. Orexin and sleep. Switzerland: Springer International Publishing 2015.

90. Kushikata T, Hirota K, Yoshida H, Kudo M, Lambert DG, Smart D, et al. Orexinergic neurons and barbiturate anesthesia. Neuroscience 2003; 121:855-63.

91. Kushikata T, Yoshida H, Kudo M, Kudo T, Kudo T, Hirota K. Role of coerulean noradrenergic neurones in general anaesthesia in rats. $\mathrm{Br} J$ Anaesth 2011;107:924-9.

92. Zecharia AY, Nelson LE, Gent TC, Schumacher M, Jurd R, Rudolph U, et al. The involvement of hypothalamic sleep pathways in general anesthesia: testing the hypothesis using the GABAA receptor beta3N265M knock-in mouse. J Neurosci 2009;29:2177-87.

93. Shirasaka T, Yonaha T, Onizuka S, Tsuneyoshi I. Effects of orexin-A on propofol anesthesia in rats. J Anesth 2011;25:65-71.
94. Dong H, Niu J, Su B, Zhu Z, Lv Y, Li Y, et al. Activation of orexin signal in basal forebrain facilitates the emergence from sevoflurane anesthesia in rat. Neuropeptides 2009;43:179-85.

95. Dong HL, Fukuda S, Murata E, Zhu Z, Higuchi T. Orexins increase cortical acetylcholine release and electroencephalographic activation through orexin-1 receptor in the rat basal forebrain during isoflurane anesthesia. Anesthesiology 2006;104:1023-32.

96. Kelz MB, Sun Y, Chen J, Cheng Meng Q, Moore JT, Veasey SC, et al. An essential role for orexins in emergence from general anesthesia. Proc Natl Acad Sci USA 2008;105:1309-14.

97. Gompf H, Chen J, Sun Y, Yanagisawa M, Aston-Jones G, Kelz MB. Halothane-induced hypnosis is not accompanied by inactivation of orexinergic output in rodents. Anesthesiology 2009;111:1001-9.

98. Cavalcante AN, Hofer RE, Tippmann-Peikert M, Sprung J, Weingarten TN. Perioperative risks of narcolepsy in patients undergoing general anesthesia: A case-control study. J Clin Anesth 2017;41:120-5.

99. Burrow B, Burkle C, Warner DO, Chini EN. Postoperative outcome of patients with narcolepsy. A retrospective analysis. J Clin Anesth 2005; 17:21-5.

100. Peláez R, Hortal FJ, Bastida E, Barrio JM, Riesgo MJ. Narcolepsy and cardiac surgery: can anesthesia with propofol and remifentanil be safe? J Cardiothorac Vasc Anesth 2004;18:201-3.

101. Hu S, Singh M, Wong J, Auckley D, Hershner S, Kakkar R, et al. Anesthetic management of narcolepsy patients during surgery: a systematic review. Anesth Analg 2018;126:233-46.

102. Kuroki C, Takahashi Y, Ootsuka Y, Kanmura Y, Kuwaki T. The impact of hypothermia on emergence from isoflurane anesthesia in orexin neuron-ablated mice. Anesth Analg 2013;116:1001-5.

103. Morimoto Y, Nogami Y, Harada K, Shiramoto H, Moguchi T. Anesthetic management of a patient with narcolepsy. J Anesth 2011;25:435-7.

104. Kobayashi K, Takemori K, Sakamoto A. Circadian gene expression is suppressed during sevoflurane anesthesia and the suppression persists after awakening. Brain Res 2007;1185:1-7.

105. Poulsen RC, Warman GR, Sleigh J, Ludin NM, Cheeseman JF. How does general anaesthesia affect the circadian clock? Sleep Med Rev 2018; 37:35-44.

106. Dispersyn G, Pain L, Challet E, Touitou Y. General anesthetics effects on circadian temporal structure: an update. Chronobiol Int 2008;25: 835-50.

107. Ram E, Vishne TH, Weinstein T, Beilin B, Dreznik Z. General anesthesia for surgery influences melatonin and cortisol levels. World $J$ Surg 2005;29:826.

108. Mowafi HA, Ismail SA. Melatonin improves tourniquet tolerance and enhances postoperative analgesia in patients receiving intravenous regional anesthesia. Anesth Analg 2008;107:1422-6.

109. Sultan SS. Assessment of role of perioperative melatonin in prevention and treatment of postoperative delirium after hip arthroplasty under spinal anesthesia in the elderly. Saudi J Anaesth 2010;4:169-73.

110. Hanania M, Kitain E. Melatonin for treatment and prevention of postoperative delirium. Anesth Analg 2002;94:338-9.

111. Özcengiz D, Gunes Y, Ozmete O. Oral melatonin, dexmedetomidine, and midazolam for prevention of postoperative agitation in children. $J$ Anesth 2011;25:184-8.

112. Yon JH, Carter LB, Reiter RJ, Jevtovic-Todorovic V. Melatonin reduces the severity of anesthesia-induced apoptotic neurodegeneration in the developing rat brain. Neurobiol Dis 2006;21:522-30.

113. Ni C, Tan G, Luo A, Qian M, Tang Y, Zhou Y, et al. Melatonin premedication attenuates isoflurane anesthesia-induced $\beta$-amyloid generation and cholinergic dysfunction in the hippocampus of aged rats. Int J Neurosci 2013;123:213-20.

114. Ismail SA, Mowafi HA. Melatonin provides anxiolysis, enhances analgesia, decreases intraocular pressure, and promotes better operating conditions during cataract surgery under topical anesthesia. Anesth Analg 2009;108:1146-51.

115. Högl B, Frauscher B, Seppi K, Ulmer H, Poewe W. Transient restless 
legs syndrome after spinal anesthesia: a prospective study. Neurology 2002;59:1705-7.

116. Watanabe S, Ono A, Naito H. Periodic leg movements during either epidural or spinal anesthesia in an elderly man without sleep-related (nocturnal) myoclonus. Sleep 1990;13:262-6.

117. Moorthy SS, Dierdorf SF. Restless legs during recovery from spinal anesthesia. Anesth Analg 1990;70:337.

118. Raux M, Karroum EG, Arnulf I. Case scenario: anesthetic implications of restless legs syndrome. Anesthesiology 2010;112:1511-7.

119. Montplaisir J, Lapierre O, Warnes H, Pelletier G. The treatment of the restless leg syndrome with or without periodic leg movements in sleep. Sleep 1992;15:391-5.

120. Ross DA, Narus MS, Nutt JG. Control of medically refractory restless legs syndrome with intrathecal morphine: case report. Neurosurgery 2008;62:E263.

121. Kapur N, Friedman R. Oral ketamine: a promising treatment for rest- less legs syndrome. Anesth Analg 2002;94:1558-9.

122. Gupta RM, Parvizi J, Hanssen AD, Gay PC. Postoperative complications in patients with obstructive sleep apnea syndrome undergoing hip or knee replacement: a case-control study. Mayo Clin Proc 2001; 76:897-905.

123. Connolly LA. Anesthetic management of obstructive sleep apnea patients. J Clin Anesth 1991;3:461-9.

124. Joshi GP, Ankichetty SP, Gan TJ, Chung F. Society for Ambulatory Anesthesia consensus statement on preoperative selection of adult patients with obstructive sleep apnea scheduled for ambulatory surgery. Anesth Analg 2012;115:1060-8.

125. Chung SA, Yuan H, Chung F. A systemic review of obstructive sleep apnea and its implications for anesthesiologists. Anesth Analg 2008; 107:1543-63.

126. Adesanya AO, Lee W, Greilich NB, Joshi GP. Perioperative management of obstructive sleep apnea. Chest 2010;138:1489-98. 